\title{
Gastroschisis Associated with Cleft Lip and Palate: Report of Three Cases
}

\author{
Kouamé Soroboua Agbara*, Martial Olivier Moulot, Adjoba Manuela Ehua, Jean Marie Konan, \\ Ibrahim Traoré, Franck Grah, Anon Ghislain Anon, Josaphat Konvolbo, Robert Boulleys, \\ Idalia Ajoumissi, Alphamoyé Haidara, Paule-Christine Ekobo, Sanni Roumanatou Bankolé
}

Félix Houpouet Boigny University, Cocody/Abidjan, Ivory Coast

Email:^agbara@ymail.com

How to cite this paper: Agbara, K.S., Moulot, M.O., Ehua, A.M., Konan, J.M., Traoré, I., Grah, F., Anon, A.G., Konvolbo, J., Boulleys, R., Ajoumissi, I., Haidara, A., Ekobo, P.-C. and Bankolé, S.R. (2019) Gastroschisis Associated with Cleft Lip and Palate: Report of Three Cases. Open Journal of Pediatrics, 9, 1-6.

https://doi.org/10.4236/ojped.2019.91001

Received: December 22, 2018

Accepted: January 11, 2019

Published: January 14, 2019

Copyright $\odot 2019$ by author(s) and Scientific Research Publishing Inc. This work is licensed under the Creative Commons Attribution International License (CC BY 4.0).

http://creativecommons.org/licenses/by/4.0/

\begin{abstract}
Gastroschisis is a malformation of the abdominal wall like omphalocele. In most cases, gastroschisis is isolated. But in some cases, we find malformations, essentially minor and concern gastrointestinal or genitourinary systems. Association with craniofacial congenital midline defects is uncommon. We report 3 cases of association between gastroschisis and cleft lip and palate for the benefit of the scientific community. Two 0-day-old and a 1-day newborns were admitted in our institution for malformation of face and abdominal wall. The physical examination confirmed the association of gastroschisis and cleft lip and palate. The patients underwent primary closure. Other malformations could not be sought until all patients died.
\end{abstract}

\section{Keywords}

Gastroschisis, Cleft Lip and Palate, Primary Closure

\section{Introduction}

Gastroschisis is an abdominal wall defect presenting in the majority of cases to the right of the umbilical cord. It is thought to result from an ischemic insult to the developing body wall. However cases of left-sided gastroschisis have been reported. The incidence of gastroschisis ranges between 0.4 and 3 per 10,000 births [1] [2]. Etiology of this abdominal wall defect is unknown. Associated pathologies are around $10 \%$ and most of the anomalies are in the gastrointestinal tract [3]. Other malformations are uncommon. The association with cleft lip and palate is rarely described in literature. The objective is to report 3 cases of Gastroschisis associated with cleft lip and palate, which is not frequent and management difficulties in our condition at Treichville Teaching Hospital of Ivory 
Coast.

\section{Case Reports}

\subsection{Case 1}

A female newborn has been received at 9 hours of life for a congenital abdominal and facial malformation. She was born of a non followed pregnancy, without ultrasound and prophylaxis. The baby was delivered at term in cephalic presentation. After finding the facial and abdominal malformation, the newborn was referred in our service.

We noted a hypothermic neonate $\left(35^{\circ} \mathrm{C}\right)$ with cyanosis and a weight of $2300 \mathrm{~g}$. A bilateral cleft lip and palate and gastroschisis with a defect of $4 \mathrm{~cm}$ to the right of the umbilical cord was found in respiratory distress (Figure 1). Meconium has been emitted during the physical examination. No other congenital anomalies were found and Laboratory exam (serum electrolytes, blood count) was normal.

It was admitted in neonatology. Primary closure of gastroschisis was successful with abdominal tension (Figure 2). Nutrition by amino acids and glucose serum $10 \%$ was instituted.

The newborn died on the fifth day in a context of sepsis with respiratory distress.

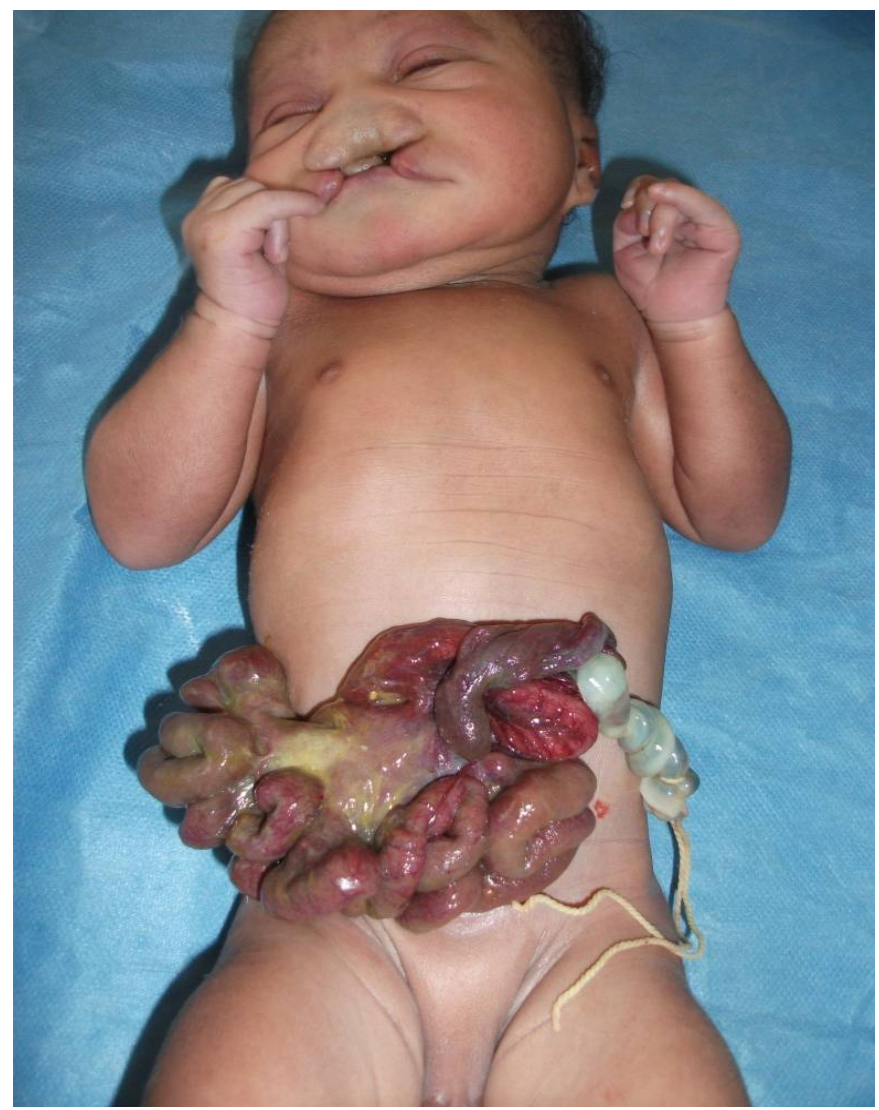

Figure 1. Gastroschisis with bilateral cleft lip and palate. 


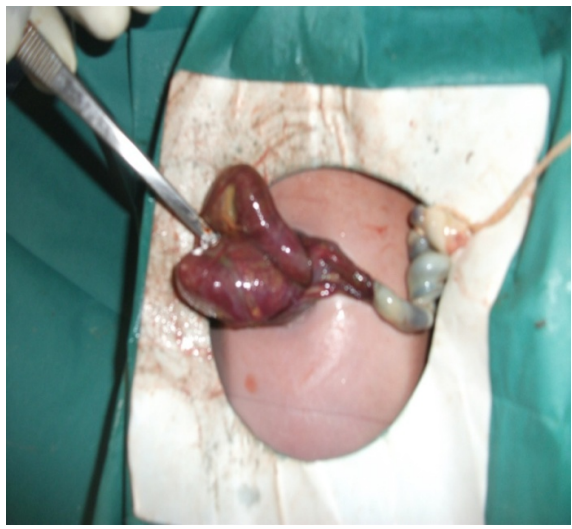

(a)

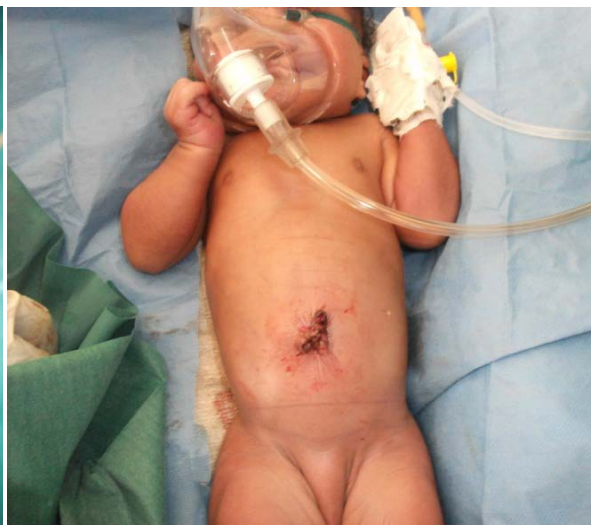

(b)

Figure 2. Primary closure ((a) During integration; (b) Post operative image).

\subsection{Case 2}

A female newborn has been received at 4 hours of life for a congenital malformation. Pregnancy was followed, with ultrasound, tetanus and malarial prophylaxis. An antenatal ultrasound was performed and was normal. The baby was delivered normally at full term with a weight of $3150 \mathrm{~g}$. APGAR score was 3-4-6 in 10 minutes. Malformations were observed by the midwife at the birth. She was first resuscitated and then addressed to us.

Physical exam showed a newborn with a bad general impression, with archaic reflexes absent, cyanotic, with severe bradycardia. Also two congenital malformations are diagnosed, such as left cleft lip and gastroschisis with a defect of 4 $\mathrm{cm}$ to the right of the umbilical cord. No other congenital anomalies were found. No meconium emitted. Laboratory exam (serum electrolytes, blood count) was normal.

In emergency, it was admitted in resuscitation room for management with closing of the bowel by sterile glove. The newborn died 4 hours later in a context of brain suffering.

\subsection{Case 3}

A 1-day-old boy was admitted for a malformation of the face and abdominal wall. Mother age was 25 years and it was her first childbirth. The prenatal pregnancy follow-up was uneventful, and the obstetric ultrasound was normal. The baby was delivered normally at term and addressed to our service but arrived the next day without special care.

Physical exam showed bilateral cleft lip and palate associated to gastroschisis with a defect of $3 \mathrm{~cm}$ to the right of the umbilical cord (Figure 3). Laboratory exam (serum electrolytes, blood count) was normal.

A primary closure of gastroschisis was successful, and the cleft lip and palate repair was programmed after three months.

The patient died at 15 days of age, due to a problem of parenteral nutrition and sepsis. Other malformations have not been researched. 


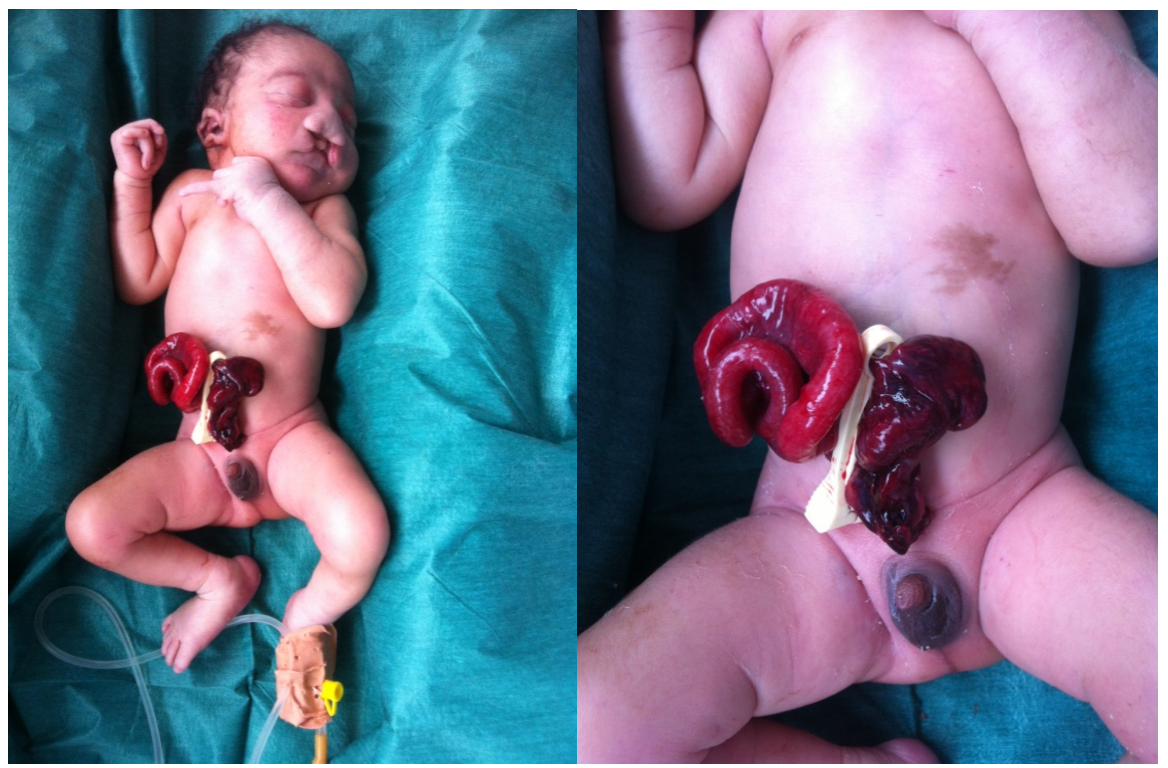

Figure 3. Gastroschisis associated to bilateral cleft lip and palate.

\section{Discussion}

Gastroschisis is abdominal wall malformation which occurs late in embryonic development. It occurs after normal reintegration of bowel. The abdominal wall is well formed between the 10th to 12th week, and the intestine returns to the abdominal cavity [4]. Many controversial theories have been proposed. Mesodermal body wall deficiency and vascular disruption are more accepted. It results from all that, generally gastroschisis is felt to have a very low rate of associated malformation and less gravity. The associated anomalies usually reported including: intestinal stenosis or atresia [5], undescended testes, Meckel's diverticulum, and intestinal duplications. Chromosomal abnormalities are unusual [6] [7].

Unlike gastroschisis, omphalocele occurs early without first reintegration. Because of this early onset, it is associated with various other malformations of all systems in 50 à $70 \%$. Chromosome anomalies (trisomy 13,14, 15, 18, and 21), Cardiac defects (atrial or ventricular septal defects, ectopiacordis, coarctation, tricuspid valve atresia), cryptorchidism, gastroesophageal reflux, macrosomia, neural tube defects, and musculoskeletal anomalies are regularly present. It can be associated in syndrome such as Beckwith-Wiedemann syndrome [8] [9] [10].

Association between cleft lip and palate with gastroschisis is uncommon and rarely described in the literature. The both pathologies are not the same period of appearance. In fact the face is fully formed by the eighth week. Teratogens (ethanol, thalidomide, phenytoin) exposure and environmental factors (Amniotic banding, maternal diabetes, maternal folate deficiency, smoking) have also been linked to cleft formation. Cleft lip and palate is reported to occur in approximately 1 in 700 live births. This prevalence varies according to the race, geographic origin, infant sex and the family's socio-economic status [5]. It can be associated with other anomalies including: cardiovascular (24\% - 51\%), mus- 
culoskeletal, facial dysmorphia or genitourinary system disturbance. Cleft cases are syndromic in 15\% and are found in over 400 syndromes [11] [12].

The rare association of gastroschisis and cleft lip and palate should be explored in search of favoring factors or chromosomal malformations. Thus new syndromic associations could be highlighted. This association may be a coincidental occurrence. But a teratogenic effect may be responsible. In our study, the rapid death of the 3 patients did not allow to explore them.

The success of gastroschisis management is around $100 \%$ in developed countries [13]. In our context, with a silo unavailability and a lack of parental nutrition, the survival remains at $0 \%$. With the modern hospital dedicated for children in our country, we hope for a better prognosis.

\section{Conclusion}

Gastroschisis, abdominal wall defect, is an isolated malformation in the most of cases. The associated malformations usually reported concern the digestive tract. The association with cleft lip and palate although still rare must to be explored in front of the growing incidence. Other syndromic associations could be revealed.

\section{Conflicts of Interest}

The following authors have no financial disclosures: (K S A, M O M, A M E, JM K, I T; F G, R B, G A A, A H, I A, K J, PC E, B S R).

\section{Patient Consent}

Consent to publish the case report was obtained with 2 parents. The last (case 2) did not accept. This report does not contain any personal information that could lead to the identification of the patient.

\section{Funding}

No funding or grant support.

\section{Authorship}

All authors attest that they meet the current ICMJE criteria for Authorship.

\section{References}

[1] Friedman, A.M., Amanth, C.V., Siddiq, Z., D’Alton, M.E. and Wright, J.D. (2016) Gastroschisis: Epidemiology and Mode of Delivery, 2005-2013. American Journal of Obstetrics and Gynecology, 215, 348.e1-e9. https://doi.org/10.1016/j.ajog.2016.03.039

[2] Yoshioka, H., Aoyama, K. and Iwamura, Y. (2004) Two Cases of Left Sided Gastroschisis: Review of the Literature. Pediatric Surgery International, 20, 472-473. https://doi.org/10.1007/s00383-004-1181-Z

[3] Molik, K.A., Gingalewski, C.A. and West, K.W. (2001) Gastroschisis: A Plea for Risk Categorization. Journal of Pediatric Surgery, 36, 51-55.

https://doi.org/10.1053/jpsu.2001.20004 
[4] Vermeij-Keers, C., Hartwig, N.G. and Van der Werff, J.F. (1996) Embryonic Development of the Ventral Body Wall and Its Congenital Malformations. Seminars in Pediatric Surgery, 5, 82-89.

[5] Bender, P.L. (2000) Genetics of Cleft Lip and Palate. Journal of Pediatric Nursing, 15, 242-249. https://doi.org/10.1053/jpdn.2000.8148

[6] Akhtar, J. and Skarsgard, E.D. (2012) Associated Malformations and the "Hidden Mortality" of Gastroschisis. Journal of Pediatric Surgery, 47, 911-916. https://doi.org/10.1016/j.jpedsurg.2012.01.044

[7] Snyder, C.L., Miller, K.A. and Sharp, R.J. (2001) Management of Intestinal Atresia in Patients with Gastroschisis. Journal of Pediatric Surgery, 36, 1542-1545. https://doi.org/10.1053/jpsu.2001.27040

[8] Hwang, P.J. and Kousseff, B.G. (2004) Omphalocele and Gastroschisis: An 18-Year Review Study. Genetics in Medicine, 6, 232-236. https://doi.org/10.1097/01.GIM.0000133919.68912.A3

[9] Nicolaides, K.H., Snijders, R.J. and Cheng, H.H. (1992) Fetal Gastro-Intestinal and Abdominal Wall Defects: Associated Malformations and Chromosomal Abnormalities. Fetal Diagnosis and Therapy, 7, 102-115. https://doi.org/10.1159/000263657

[10] Hardy, D., Bhalla, V.K., Parkhurst, C., Pipkin, W.L., Howell, C.G. and Hatley, R.M. (2014) Gastroschisis Associated with an Omphalocele and Intestinal Atresia. Pediatric Surgery International, 30, 353-355. https://doi.org/10.1007/s00383-013-3350-4

[11] Stoll, C., Alembik, Y., Dott, B. and Roth, M.P. (2000) Associated Malformations in Cases with Oral Clefts. The Cleft Palate-Craniofacial Journal, 37, 41-47. https://doi.org/10.1597/1545-1569_2000_037_0041_amicwo_2.3.co_2

[12] Hodgkinson, P.D., Brown, S., Duncan, D., Grant, C., McNaughton, A., Thomas, P. and Mattick, C.R. (2005) Management of Children with Cleft Lip and Palate: A Review Describing the Application of Multidisciplinary Team Working in This Condition Based upon the Experiences of a Regional Cleft Lip and Palate Centre in the United Kingdom. Fetal and Maternal Medicine Review, 16, 1-27. https://doi.org/10.1017/S0965539505001452

[13] Ford, K., Poenaru, D., Moulot, O., Tavener, K., Bradley, S., Bankole, R.., Tshifularo, N., Ameh, E., Alema, N., Borgstein, E., Hickey, A. and Ade-Ajay, N. (2016) Gastroschisis: Bellwether for Neonatal Surgery Capacity in Low Resource Settings? JPS, 51, 1262-1267. 